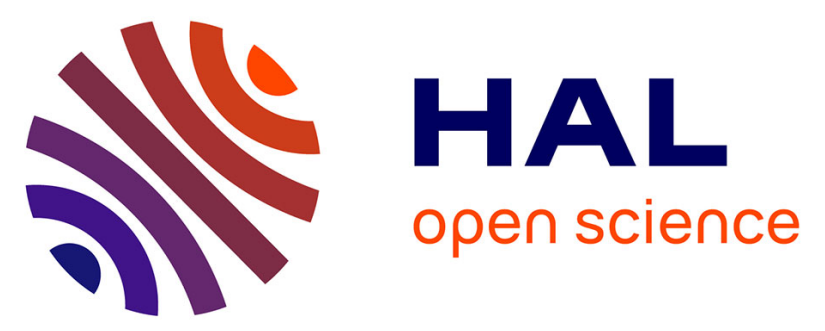

\title{
Plasma Waves Near the Electron Cyclotron Frequency in the Near Sun Solar Wind: Wave Mode Identification and Driving Instabilities
}

David Malaspina, Lynn Wilson, Robert Ergun, Stuart Bale, John Bonnell, Thierry Dudok de Wit, Keith Goetz, Katherine Goodrich, Peter Harvey, Robert Macdowall, et al.

\section{To cite this version:}

David Malaspina, Lynn Wilson, Robert Ergun, Stuart Bale, John Bonnell, et al.. Plasma Waves Near the Electron Cyclotron Frequency in the Near Sun Solar Wind: Wave Mode Identification and Driving Instabilities. vEGU21, 2021, Online, France. 10.5194/egusphere-egu21-955 . insu-03559380

\section{HAL Id: insu-03559380 \\ https://hal-insu.archives-ouvertes.fr/insu-03559380}

Submitted on 6 Feb 2022

HAL is a multi-disciplinary open access archive for the deposit and dissemination of scientific research documents, whether they are published or not. The documents may come from teaching and research institutions in France or abroad, or from public or private research centers.
L'archive ouverte pluridisciplinaire HAL, est destinée au dépôt et à la diffusion de documents scientifiques de niveau recherche, publiés ou non, émanant des établissements d'enseignement et de recherche français ou étrangers, des laboratoires publics ou privés.

\section{(c)(1)}

Distributed under a Creative Commons Attribution| 4.0 International License 
EGU21-955

https://doi.org/10.5194/egusphere-egu21-955

EGU General Assembly 2021

(c) Author(s) 2022. This work is distributed under

the Creative Commons Attribution 4.0 License.

\title{
Plasma Waves Near the Electron Cyclotron Frequency in the Near Sun Solar Wind: Wave Mode Identification and Driving Instabilities
}

\author{
David Malaspina ${ }^{1,2}$, Lynn Wilson ${ }^{3}$, Robert Ergun ${ }^{1,2}$, Stuart Bale ${ }^{4,5}$, John Bonnell ${ }^{4}$, Thierry Dudok de \\ Wit $^{6}$, Keith Goetz ${ }^{7}$, Katherine Goodrich ${ }^{4}$, Peter Harvey ${ }^{4}$, Robert MacDowall ${ }^{3}$, Marc Pulupa ${ }^{4}$, Jasper \\ Halekas ${ }^{8}$, Anthony Case ${ }^{9}$, Davin Larson ${ }^{4}$, Michael Stevens ${ }^{9}$, and Phyllis Whittlesey ${ }^{4}$ \\ ${ }^{1}$ Astrophysical and Planetary Sciences Department, University of Colorado, Boulder, Colorado, USA \\ (david.malaspina@colorado.edu) \\ ${ }^{2}$ Laboratory for Atmospheric and Space Physics, University of Colorado, Boulder, Colorado, USA \\ (david.malaspina@colorado.edu) \\ ${ }^{3}$ NASA Goddard Space Flight Center, Greenbelt, Maryland, USA (lynn.b.wilsoniii@gmail.com) \\ ${ }^{4}$ Space Sciences Laboratory, University of California Berkeley, Berkeley, California, USA (bale@berkeley.edu) \\ ${ }^{5}$ Physics Department, University of California, Berkeley, California, USA (bale@berkeley.edu) \\ ${ }^{6}$ LPC2E, CNRS, and University of Orleans, Orleans, France (ddwit@cnrs-orleans.fr) \\ ${ }^{7}$ School of Physics and Astronomy, University of Minnesota, Minneapolis, Minnesota, USA (goetz@umn.edu) \\ ${ }^{8}$ Department of Physics \& Astronomy, University of lowa, lowa City, lowa, USA (jasper-halekas@uiowa.edu) \\ ${ }^{9}$ Harvard-Smithsonian Center for Astrophysics, Cambridge, Massachusetts, USA (tonycase@cfa.harvard.edu)
}

Recent studies of the solar wind sunward of $0.25 \mathrm{AU}$ using the Parker Solar Probe spacecraft reveal that that solar wind can be bimodal, alternating between near quiescent regions with low turbulent fluctuation amplitudes and Parker-like magnetic field direction and regions of highly turbulent plasma and magnetic field fluctuations associated with 'switchbacks' of the radial magnetic field.

The quiescent solar wind regions are highly unstable to the formation of plasma waves near the electron cyclotron frequency (fce), possibly driven by strahl electrons, which carry the solar wind heat flux, and may provide one of the most direct particle diagnostics of the solar corona at the source of the solar wind. These waves are most intense near $\sim 0.7 \mathrm{fce}$ and $\sim \mathrm{fce}$. The near-fce waves are found to become more intense and more frequent closer to the Sun, and statistical evidence indicates that their occurrence rate is related to the sunward drift of the core electron population.

In this study, we examine high time resolution burst captures of these waves, demonstrating that each wave burst contains several distinct wave types, including electron Bernstein waves and extremely narrow band waves that are highly sensitive to the magnetic field orientation. Using properties of these waves we provide evidence to support the identification of their likely plasma wave modes and the instabilities responsible for generating these waves. By understanding the driving instabilities responsible for these waves, we infer their ability to modify electron distribution functions in the quiescent near-Sun solar wind. 
